\title{
Neck Circumference Percentiles of Iranian Children and Adolescents: The Weight Disorders Survey of CASPIAN IV Study
}

\author{
Mostafa Hosseini, ${ }^{1,2}$ Mohammad Esmail Motlagh, ${ }^{3}$ Mahmoud Yousefifard, ${ }^{4}$ Mostafa Qorbani, ${ }^{5,6,}$ \\ Neamatollah Ataei, ${ }^{1,7}$ Hamid Asayesh, ${ }^{8}$ Mehdi Yaseri, ${ }^{2}$ Rasool Mohammadi, ${ }^{9}$ Masoud Baikpour, ${ }^{10}$ \\ Arash Abbasi, ${ }^{7}$ and Roya Kelishadi ${ }^{11, * *}$ \\ ${ }^{1}$ Pediatric Chronic Kidney Disease Research Center, the Children's Hospital Medical Center, Tehran University of Medical Sciences, Tehran, Iran \\ ${ }^{2}$ Department of Epidemiology and Biostatistics, School of Public Health, Tehran University of Medical Sciences, Tehran, Iran \\ ${ }^{3}$ Department of Pediatrics, Ahvaz Jundishapur University of Medical Sciences, Ahvaz, Iran \\ ${ }^{4}$ Physiology Research Center and Department of Physiology, Faculty of Medicine, Iran University of Medical Sciences, Tehran, Iran \\ ${ }^{5}$ Non-communicable Diseases Research Center, Alborz University of Medical Sciences, Karaj, Iran \\ ${ }^{6}$ Chronic Diseases Research Center, Endocrinology and Metabolism Population Sciences Institute, Tehran University of Medical Sciences, Tehran, Iran \\ ${ }^{7}$ Department of Pediatric Nephrology, The Children's Hospital Medical Center, Faculty of Medicine, Tehran University of Medical Sciences, Tehran, Iran \\ ${ }^{8}$ Department of Medical Emergencies, Qom University of Medical Sciences, Qom, Iran \\ ${ }^{9}$ Department of Epidemiology, School of Public Health, Shahid Beheshti University of Medical Sciences, Tehran, Iran \\ ${ }^{10}$ Department of Medicine, School of Medicine, Tehran University of Medical Sciences, Tehran, Iran \\ ${ }^{11}$ Child Growth and Development Research Center, Research Institute for Primordial Prevention of Non-communicable Disease, Isfahan University of Medical Sciences, \\ Isfahan, Iran \\ "Corresponding author: Mostafa Qorbani, Non-communicable Diseases Research Center, Alborz University of Medical Sciences, Karaj, Iran. E-mail: \\ mostafaqorbani1379@gmail.com \\ ${ }^{* *}$ Corresponding author: Roya Kelishadi, Child Growth and Development Research Center, Research Institute for Primordial Prevention of Non-communicable Disease, Isfahan \\ University of Medical Sciences, Isfahan, Iran. E-mail: kelishadi@med.mui.ac.ir
}

Received 2017 February 15; Revised 2017 May 16; Accepted 2017 July 11.

\begin{abstract}
Background: Neck circumference (NC), emerging as a key morphological index for pediatric obesity, is associated with obesityand overweight-related detrimental conditions in children. In this study, we aimed to provide the age- and sex-specific percentile reference values for neck circumference of the Iranian children and adolescents.

Methods: We used the data gathered through the weight disorders survey of CASPIAN IV study conducted in 2011 - 2012 in Iran, including a total of 21954 Iranian children and adolescents, composed of 10750 girls and 11204 boys, aged 7 - 18 years old. We presented the interval of NC percentile in three age groups of 7 - 10 years, 11 - 14 years, and 15 - 18 years. Finally, age-specific nomograms of NC for both genders in the Iranian and Canadian populations were compared.

Results: The intervals of 90th percentile of NC for boys in the three periods of school age (7-10 years), pre-adolescence (11-14 years), and adolescence (15 - 18 years) were $24.2-30.0 \mathrm{~cm}, 26.6-33.2 \mathrm{~cm}$, and $30.1-38.5 \mathrm{~cm}$, respectively. These intervals for girls were 23.7 $-30.1 \mathrm{~cm}, 26.5-33.7 \mathrm{~cm}$, and $28.5-36.0 \mathrm{~cm}$, respectively. NC increased with age in both boys and girls and its variability showed an increasing trend with age.

Conclusions: We demonstrated for the first time the NC reference values for the Iranian children and adolescents aged 7 - 18 years old. Considering the significant differences between our national NC references and the values reported from the Canadian population, it seems logical to use these national percentiles not only for epidemiologic studies but also for routine clinical examinations.
\end{abstract}

Keywords: Neck Circumference, Anthropometric Measures, Obesity, Children and Adolescence

\section{Background}

Overweight and obesity are known to be associated with various risk factors for later metabolic and cardiovascular disorders, and their prevalence continues to rise among Iranian children and adolescents (1). Therefore, close monitoring in childhood seems to be of utmost importance to prevent long-term complications of the obe- sity.

The most commonly used criteria for identification of overweight and obesity is the body mass index (BMI). However, the risk of multiple cardiovascular and metabolic disturbances has been found to be correlated with body fat distribution rather than just overweight and obesity $(2,3)$, and the BMI seems to be deficient in this regard (4-6); thus, 
clinical decision-making cannot be solely relied upon this index $(7,8)$. Accordingly, several anthropometric indices have been proposed to provide further information on the characteristics of subjects including waist circumference (WC), skinfold thickness, and mid-upper arm circumference (MUAC) (9). Of these, WC and MUAC were reported to be useful in detection of central obesity, but measuring WC was found to be challenging, particularly in children $(10,11)$. Therefore, search for a simple and easily measured index for optimal classification of children continued. In this regard, neck circumference (NC) emerged to be a promising possible alternative indicator for pediatric obesity (12). NC measurements were found to exert some advantages over those traditional indices (12) and it is particularly helpful for prediction of obstructive sleep apnea in children, due to its etiological links with fat distribution in the neck $(13,14)$. Moreover, since larger sizes of neck have been shown to be associated with pediatric obesity $(12,15$, 16), metabolic risk factors (17), cardiovascular diseases (1820), obstructive sleep apnea (14) and age- and sex-specific reference values of $\mathrm{NC}$ might be applicable in prediction of these outcomes.

$\mathrm{NC}$ nomograms have been developed for specific populations in Turkey (15), Canada (12), and Europe (21). To date, no valid standard references have been developed for NC measurements of Iranian children and adolescents. This study aimed to develop age- and sex-specific percentile reference values for neck circumference of Iranian children and adolescents. In addition, we aimed to compare the NC values of the Iranian children with the references of the Canadian population.

\section{Methods}

\subsection{Study Population}

Data from 21954 Iranian children and adolescents (including 10750 girls and 11204 boys between 7 and 18 years of age) were gathered through a national survey on weight disorders. The survey was conducted in $2011-2012$ $(22,23)$ as a complementary of a national school-based surveillance program entitled Childhood and Adolescence Surveillance and PreventIon of Adult Non-communicable disease (CASPIAN-IV survey). Study population and sampling framework were reported in Kelishadi et al. study (23). Briefly, in these surveys, multistage cluster sampling from urban and rural areas of 30 provinces of Iran was performed. Exclusion criteria in these surveys included having a chronic disease, history of chronic medication consumption, and being on a special diet. Participation rate was $90.6 \%$.

The protocols of the present study were approved by research ethics committee of Isfahan and Alborz University of Medical Sciences. Informed consent was obtained from parents of the children or their guardians.

\subsection{Measurements}

All measurements were recorded by trained physicians using calibrated devices. Detailed description of procedure and measurements were presented in previous article (22). Briefly, the height $(\mathrm{cm})$ without shoes was measured using a stadiometer (SECA Model 207, Hamburg, Germany) while the child standing upright with the heels and back against a vertical scale. The weight was measured without shoes and heavy outer clothing by a balanced scale (SECA Model 710, Germany) that was calibrated daily. A Gulick measuring tape was used to measure $\mathrm{NC}$ with an accuracy of 0.1 centimeters $(\mathrm{cm})$ with the most prominent portion of the thyroid cartilage taken as a landmark. WC $(\mathrm{cm})$ was measured at the top of the iliac crest as a landmark. We calculated BMI by dividing weight $(\mathrm{kg})$ by height squared $\left(\mathrm{m}^{2}\right)$.

\subsection{Statistical Analysis}

In order to elicit sex-specific smoothed percentiles for age, the Lambda-Mu-Sigma (LMS) method of Cole and Green was used (24). In this method, three curves are utilized to demonstrate the trend of changes in NCs of the study population. The skewness, the median, and the coefficient of variation are defined as functions of age by the $\mathrm{L}, \mathrm{M}$, and $\mathrm{S}$ curves, respectively.

Since we included data from the age group of 7 to 18 years, to compare our data with the Canadian study, agecompatible subjects were chosen from our survey including the children and adolescents aged 7 to 17 years old.

The standard curves for NC of Canadian children were presented by Katz et al. in 2014 based on the data gathered from 1913 boys and girls aged 6 to 17 years old through the second cycle of the Canadian health measures survey. Data collection was performed by home visits, the details of which are further described in previous studies (12).

Age- and gender-specific percentiles (5th, 10th, 25th, 50th, 75th, 90th, and 95th) of NC were calculated and the curves were drawn. The goodness-of-fit and the normality of the Z-Scores were examined via Chi square test and de-trended Q-Q plot, respectively. Since 90th and 95th percentiles are considered as the borderline and high values in anthropometric measurements, the results of the present study are mostly reported in these percentiles.

Lambda-Mu-Sigma Chart Maker Pro program (version 2.54, medical research council, Cambridge, UK) was used to develop smoothed age-specific percentiles of NC for both genders. Descriptive statistics were calculated by the STATA (11.0) software and then the percentile curve graphs for these data were plotted. 


\section{Results}

Data gathered from a total of 21954 Iranian children and adolescents (including 10750 girls and 11204 boys aged between 7 and 18 years) through a survey conducted from 2011 to 2012 were analyzed. Table 1 shows the baseline characteristics of the study children and adolescents. NC percentiles by age are presented for both genders in Table 2 . Age- and sex-specific NC nomograms are also depicted in Figure 1.

Table 1. Baseline Characteristics of Study Children and Adolescents

\begin{tabular}{|c|c|c|c|}
\hline & \multicolumn{3}{|c|}{ Age Groups $^{\mathrm{a}}$} \\
\hline & $7-10$ & $11-14$ & $15-18$ \\
\hline \multicolumn{4}{|l|}{ Boys } \\
\hline $\mathrm{n}(\%)$ & $3622(32.3)$ & $4012(35.8)$ & $3570(31.9)$ \\
\hline Height $(\mathrm{cm})$ & $127.5(9.3)$ & $148.2(11.3)$ & $169.6(9.7)$ \\
\hline Weight (kg) & $26.6(7.4)$ & $41.7(12.6)$ & $61.2(14.3)$ \\
\hline $\begin{array}{l}\text { Body mass index } \\
\left(\mathrm{km} / \mathrm{m}^{2)}\right.\end{array}$ & $16.2(3.7)$ & $18.7(4.6)$ & $21.1(4.3)$ \\
\hline $\begin{array}{l}\text { Waist circumference } \\
(\mathrm{cm})\end{array}$ & $58.7(7.3)$ & $68.2(10.9)$ & $75.7(10.9)$ \\
\hline $\operatorname{Hip}(\mathrm{cm})$ & $68.6(7.8)$ & $80.6(10.9)$ & $90.8(10.8)$ \\
\hline Waist to hip ratio & $0.86(0.08)$ & $0.85(0.09)$ & $0.84(0.08)$ \\
\hline Waist to height ratio & $0.46(0.05)$ & $0.46(0.06)$ & $0.45(0.06)$ \\
\hline Neck circumference $(\mathrm{cm})$ & $27.5(2.2)$ & $30.2(2.8)$ & $34.5(3.2)$ \\
\hline \multicolumn{4}{|l|}{ Girls (n, \%) } \\
\hline $\mathrm{n}(\%)$ & $3303(30.7)$ & $3757(35.0)$ & $3690(34.3)$ \\
\hline Height $(\mathrm{cm})$ & $127.2(9.6)$ & $149.5(10.3)$ & $159.5(7.1)$ \\
\hline Weight (kg) & $26.4(7.3)$ & $43.0(13.1)$ & $54.6(11.4)$ \\
\hline $\begin{array}{l}\text { Body mass index } \\
\left(\mathrm{km} / \mathrm{m}^{2}\right)\end{array}$ & $16.2(3.5)$ & $19.0(4.5)$ & $21.4(4.2)$ \\
\hline $\begin{array}{l}\text { Waist circumference } \\
(\mathrm{cm})\end{array}$ & $57.7(7.3)$ & $66.8(9.4)$ & $72.2(9.3)$ \\
\hline $\operatorname{Hip}(\mathrm{cm})$ & $68.8(8.6)$ & $83.1(10.7)$ & $92.5(9.7)$ \\
\hline Waist to hip ratio & $0.84(0.10)$ & $0.81(0.08)$ & $0.78(0.09)$ \\
\hline Waist to height ratio & $0.45(0.05)$ & $0.45(0.06)$ & $0.45(0.06)$ \\
\hline Neck circumference $(\mathrm{cm})$ & $27.1(2.5)$ & $30.2(2.8)$ & $32.2(2.7)$ \\
\hline
\end{tabular}

${ }^{\mathrm{a}}$ Data were presented as mean and standard deviation.

We observed sex-related differences in NC and its growth by age. The differences of NC between boys and girls were at most $4.1 \mathrm{~cm}$ for the 90th percentile at the age of 18 years, with boys showing an $11.68 \%$ higher NC. However, the 95th percentile of girls aged 9 - 13 years indicated a slightly higher NC than that of boys $(0.3-0.7 \mathrm{~cm})$.

The maximum annual increase in NC of boys occurred during 14 and 16 years of age $(1.4 \mathrm{~cm}$ at most for the 95 th
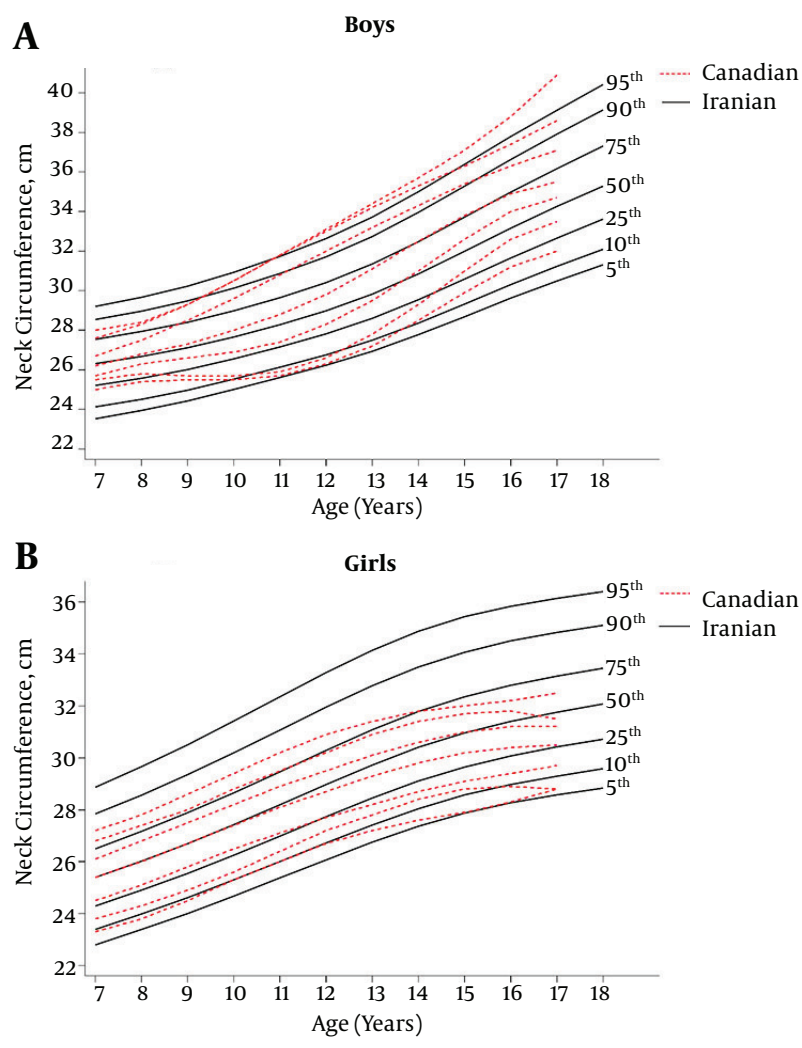

Figure 1. Comparisons of neck circumference percentile curves for Iranian children and adolescents with the Canadian reference data. Centiles are 5th, 20th, 25th, 50th, 75th, 90th, and 95th

percentile), while for girls it occurred between 11 and 12 years of age $(1 \mathrm{~cm}$ at most for the 95 th percentile). Moreover, the minimum increase of NC for girls was observed between the ages of 17 and 18 years $(0.2 \mathrm{~cm})$ in the 5 th percentile. On the contrary, the minimum growth of NC for boys was observed between the ages of 7 and 9 years ( 0.4 $0.5 \mathrm{~cm}$ ) for all the percentiles.

The maximum variability (the 95th percentile minus the 5 th percentile) of NC was observed at the age of 18 years, and it was at most $9.1 \mathrm{~cm}$ and $7.6 \mathrm{~cm}$ for boys and girls, respectively. On the other hand, the minimum variability was found at the age of 7, with $5.7 \mathrm{~cm}$ and $6.1 \mathrm{~cm}$ for boys and girls, respectively.

The NC reference intervals for boys during the three stages of age as school age ( 7 - 10 years), pre-adolescent (11 14 years), and adolescent (15 - 18 years) were $24.2-30.0 \mathrm{~cm}$, $26.6-33.2 \mathrm{~cm}$, and $30.1-38.5 \mathrm{~cm}$, respectively. These intervals for girls were $23.7-30.1 \mathrm{~cm}, 26.5-33.7 \mathrm{~cm}$, and $28.5-36.0$ $\mathrm{cm}$, respectively.

Figure 1 depicts the age-specific nomograms of NC for both genders in the Iranian and Canadian populations 
Table 2. Percentile Values of Neck Circumference $(\mathrm{cm})$ by Age and Sex for Iranian Children and Adolescents

\begin{tabular}{|c|c|c|c|c|c|c|c|}
\hline \multirow[t]{2}{*}{ Age } & \multicolumn{7}{|c|}{ Smoothed Percentiles } \\
\hline & 5th & 10th & 25th & 50th & 75th & 9oth & 95th \\
\hline \multicolumn{8}{|l|}{ Male } \\
\hline 7 & 23.5 & 24.1 & 25.2 & 26.3 & 27.5 & 28.5 & 29.2 \\
\hline 8 & 23.9 & 24.5 & 25.6 & 26.7 & 27.9 & 29 & 29.7 \\
\hline 10 & 25.0 & 25.5 & 26.6 & 27.7 & 29.0 & 30.1 & 30.9 \\
\hline 11 & 25.6 & 26.1 & 27.2 & 28.3 & 29.6 & 30.9 & 31.7 \\
\hline 12 & 26.2 & 26.8 & 27.8 & 29.0 & 30.4 & 31.7 & 32.6 \\
\hline 13 & 26.9 & 27.5 & 28.6 & 29.8 & 31.4 & 32.7 & 33.7 \\
\hline 14 & 27.8 & 28.4 & 29.5 & 30.9 & 32.5 & 34.0 & 35.0 \\
\hline 15 & 28.7 & 29.3 & 30.6 & 32.0 & 33.7 & 35.3 & 36.4 \\
\hline 16 & 29.6 & 30.3 & 31.7 & 33.2 & 35.0 & 36.6 & 37.8 \\
\hline 17 & 30.5 & 31.2 & 32.7 & 34.3 & 36.2 & 37.9 & 39.1 \\
\hline 18 & 31.3 & 32.1 & 33.6 & 35.3 & 37.3 & 39.2 & 40.4 \\
\hline \multicolumn{8}{|l|}{ Female } \\
\hline 7 & 22.8 & 23.4 & 24.3 & 25.4 & 26.5 & 27.8 & 28.9 \\
\hline 8 & 23.4 & 24.0 & 24.9 & 26.0 & 27.2 & 28.6 & 29.7 \\
\hline 9 & 24.0 & 24.6 & 25.6 & 26.7 & 27.9 & 29.3 & 30.5 \\
\hline 10 & 24.7 & 25.3 & 26.3 & 27.4 & 28.7 & 30.2 & 31.4 \\
\hline 11 & 25.4 & 26.0 & 27.0 & 28.2 & 29.5 & 31.1 & 32.3 \\
\hline 12 & 26.1 & 26.7 & 27.7 & 29 & 30.3 & 32 & 33.3 \\
\hline 14 & 27.4 & 28.0 & 29.1 & 30.4 & 31.8 & 33.5 & 34.9 \\
\hline 15 & 27.9 & 28.6 & 29.6 & 31.0 & 32.4 & 34.1 & 35.4 \\
\hline 16 & 28.3 & 29.0 & 30.1 & 31.4 & 32.8 & 34.5 & 35.8 \\
\hline 17 & 28.6 & 29.3 & 30.4 & 31.8 & 33.2 & 34.8 & 36.1 \\
\hline 18 & 28.8 & 29.6 & 30.7 & 32.1 & 33.5 & 35.1 & 36.4 \\
\hline
\end{tabular}

next to each other for comparison. Among boys, except ages of 11 and 12 years, the 5th percentile of NC was lower in the Iranian population than the Canadian subjects. The differences are highest at the age of 7 ; then they decrease to a point that the values are quite equal between the ages of 11 and 12; Finally, the differences again increase until the age of 17. On the other hand, the 95th percentile of NC is higher in Iranian boys up to the age of 11 and after that, the 95th percentile curve of Canadian boys crosses the Iranian curve and diverges up to the age of 17 . The differences between the two countries were found to be more prominent in the percentile curves of the girls. The 5 th percentile curve of Iranian girls is lower than the Canadian curve for all ages, while the opposite is observed for the 95th percentile curves where they diverge continually with the highest difference at the age of 17 .

The maximum NC difference between the two countries was observed in the 95th percentile of girls aged 12 17 years old in a way that the NC of Iranian girls is 2.4 - 3.6 $\mathrm{cm}$ higher than that of the Canadian girls. On the contrary, in the same age group, the NC of Iranian boys is $0.3-0.7 \mathrm{~cm}$ lower than that of their Canadian counterparts in the 95th percentile. During 7 - 10 years of age, Iranian boys show $0.4-1.2 \mathrm{~cm}$ higher NC than Canadian boys for the 95th percentile. Similarly, Iranian girls with 7 - 10 years of age had $1.7-2.1 \mathrm{~cm}$ higher NC than Canadian girls for the 95th percentile. 


\section{Discussion}

The present study provides the first NC percentile reference values for Iranian children and adolescents aged 7 18 years old. This is the first reference curve of NC not only in Iran, but also in Asia and Middle East and North Africa (MENA). We found considerable differences between our national NC reference intervals and the values reported from a Canadian study(12), which necessitates considering the national percentiles not only for epidemiologic studies but also for routine clinical examinations.

In line with previous studies $(12,15,21)$, NC increased with age in both genders. Moreover, NC variability showed an increasing trend over age (Figure 1). On the contrary, the curves of different percentiles of NC did not form a plateau in neither of the genders, which is incongruent with the morphological changes observed in Canadian (12) and Turkish girls (15). This plateau is compatible with the puberty pattern in female adolescents (25). However, the European girls (21) did not show this plateau for NC increase, either.

In the standard curves presented for the European population by Nagy et al. (21), the NC values increased constantly with age. Although it seems that puberty affects most anthropometric measurements, NC values in the Iranian and European populations were not affected by puberty, the mechanism of which is not clear.

As presented, for all ages, the 95th percentile of NC in the Iranian girls was higher than that of the Canadian girls, while the Iranian boys showed a slightly lower NC than the Canadian boys from the age of 12 to 17 years. The higher 95th percentile of NC in the Iranian girls is somewhat similar with the results of the Turkish study (15), which might be indicative of the important role of ethnicity, climate, and geographical differences in NC of the people.

The reference values presented in this study could be used by the Iranian physicians to identify children and adolescents with abnormal NC values; considering the significant risks of future cardiovascular and metabolic disorders associated with higher NC (26-29), preventive measures could be taken for these subjects predisposed to the aforementioned conditions. However, further studies are needed to determine the optimal cut-off points for prediction of cardiovascular, pulmonary, and metabolic outcomes.

NC measurements have been proposed by various studies as appropriate markers for screening of overweight and obesity. For instance, in a study by Taheri et al., children aged 7 - 16 years old were evaluated demonstrating that the NC values are significantly correlated with BMI and mid-upper arm circumference (30). As compared to other anthropometric factors used for obesity screening,
NC has multiple advantages. First, there is no need for the child to be fully exposed to the crowded clinics for measuring NC. Second, it was shown in the present study that this factor is not affected by physiological changes during growth and development while factors such as BMI and waist circumference are affected by these changes, such as the alterations in the height (31-34). Finally, NC is not affected by pre and postprandial effects (21).

In this study, we faced some limitations, as we could not evaluate the predictive role of NC in obesity-related outcomes. However, the representativeness of the study population, the employed standard methods, and the sufficient sample size included in this study could be mentioned as the strengths of this survey. Moreover, not evaluating children younger than 7 years of age was another limitation that should be addressed by future researchers. Finally, the effects of missing data on the findings should not be neglected; however, the participation rate of $90.6 \%$ in the present study minimized these effects.

\subsection{Conclusion}

The present study aimed to construct NC standard models for the Iranian population. The standards presented by this study could be used to improve the screening and evaluation processes of obesity and overweight status in the field of pediatrics. However, further investigations are required to determine the optimal cut-offs for NCs predicting the adverse outcomes of obesity.

\section{Acknowledgments}

We kindly appreciate Mrs. Mehrnoosh Yazdanbakhsh for her valuable help in language editing of the paper.

\section{Footnotes}

Authors' Contribution: Mostafa Hosseini, Mostafa Qorbani, Roya Kelishadi, and Neamatollah Ataei designed the study; Mohammad Esmail Motlagh, Hamid Asayesh, Rasool Mohammadi, Mostafa Qorbani, and Roya Kelishadi participated in the acquisition of data; Mostafa Hosseini and Mahmoud Yousefifard analyzed the data; Masoud Baikpour and Arash Abbasi participated in the management of data; Mahmoud Yousefifard and Masoud Baikpour wrote the first draft and revised the manuscript critically; all authors approved the final version of the manuscript to be published and accountable for all aspects of the work.

Financial Disclosure: The authors declare that they have no competing interests. 
Funding/Support: This research was supported by Tehran University of Medical Sciences and health services grant number: 94-04-184-30335.

Role of the Sponsor: Tehran University of Medical Sciences had no role in the design and conduct of the study, collection, management, and analysis of the data.

\section{References}

1. Taheri F, Kazemi T, Sadeghi H. Prevalence of overweight and obesity among primary school children in iran from 2001-2013: A systematic review. Mod Care J. 2015;12(3):139-45.

2. Kissebah AH, Vydelingum N, Murray R, Evans DJ, Hartz AJ, Kalkhoff RK, et al. Relation of body fat distribution to metabolic complications of obesity. J Clin Endocrinol Metab. 1982;54(2):254-60. doi: 10.1210/jcem54-2-254. [PubMed: 7033275].

3. Peiris AN, Struve MF, Mueller RA, Lee MB, Kissebah AH. Glucose metabolism in obesity: influence of body fat distribution. J Clin Endocrinol Metab. 1988;67(4):760-7. doi:10.1210/jcem-67-4-760. [PubMed: 3047162].

4. Hosseini M, Baikpour M, Yousefifard M, Fayaz M, Koohpayehzadeh J, Ghelichkhani P, et al. Blood pressure percentiles by age and body mass index for adults. EXCLI J. 2015;14:465-77. doi: 10.17179/excli2014635. [PubMed: 26417366].

5. Hosseini M, Baikpour M, Yousefifard M, Yaseri M, Fayaz M, Shirafkan H. Blood Pressure nomograms by Age and Weight for Iranian children and adolescents. Inter J Pediatrics. 2016;4(7):2153-66.

6. Ataei N, Baikpour M, Hosseini M, Yousefifard M, Fayaz M, Ataei F, et al. Blood Pressure Nomograms for Children and Adolescents by Age and Body Mass Index in Tehran, Iran. Iran J Public Health. 2017;46(3):368-79. [PubMed: 28435823].

7. Marques-Vidal P, Pecoud A, Hayoz D, Paccaud F, Mooser V, Waeber $\mathrm{G}$, et al. Normal weight obesity: relationship with lipids, glycaemic status, liver enzymes and inflammation. Nutr Metab Cardiovasc Dis. 2010;20(9):669-75. doi: 10.1016/j.numecd.2009.06.001. [PubMed: 19748248].

8. Romero-Corral A, Somers VK, Sierra-Johnson J, Korenfeld Y, Boarin $S$, Korinek J, et al. Normal weight obesity: a risk factor for cardiometabolic dysregulation and cardiovascular mortality. Eur Heart J 2010;31(6):737-46. doi: 10.1093/eurheartj/ehp487. [PubMed: 19933515].

9. Daniels SR, Khoury PR, Morrison JA. Utility of different measures of body fat distribution in children and adolescents. Am J Epidemiol. 2000;152(12):1179-84. [PubMed: 11130624].

10. Hatipoglu N, Mazicioglu MM, Kurtoglu S, Kendirci M. Neck circumference: an additional tool of screening overweight and obesity in childhood. Eur J Pediatr. 2010;169(6):733-9. doi: 10.1007/s00431-009-1104-z. [PubMed:19936785].

11. Rudolf MC, Walker J, Cole TJ. What is the best way to measure waist circumference? Int J Pediatr Obes. 2007;2(1):58-61. doi: 10.1080/17477160601095177. [PubMed: 17763011].

12. Katz SL, Vaccani JP, Clarke J, Hoey L, Colley RC, Barrowman NJ. Creation of a reference dataset of neck sizes in children: standardizing a potential new tool for prediction of obesity-associated diseases? BMC Pediatr. 2014;14:159. doi: 10.1186/1471-2431-14-159. [PubMed: 24952386].

13. Deegan PC, McNicholas WT. Pathophysiology of obstructive sleep apnoea. Eur Respir J. 1995;8(7):1161-78. [PubMed: 7589402].

14. Yu P, Ford G. Does neck size predict the presence and severity of OSAS in children? Sleep; 2008.Amer Acad Sleep Medicine One Westbrook Corporate Ctr, Ste 920,. USA: Westchester; .

15. Mazicioglu MM, Kurtoglu S, Ozturk A, Hatipoglu N, Cicek B, Ustunbas HB. Percentiles and mean values for neck circumference in Turkish children aged 6-18 years. Acta Paediatr. 2010;99(12):1847-53. doi: 10.1111/j.1651-2227.2010.01949.x. [PubMed: 20682008].
16. Nafiu OO, Burke C, Lee J, Voepel-Lewis T, Malviya S, Tremper KK Neck circumference as a screening measure for identifying children with high body mass index. Pediatrics. 2010;126(2):306-10. doi 10.1542/peds.2010-0242. [PubMed: 20603254].

17. Kurtoglu S, Hatipoglu N, Mazicioglu MM, Kondolot M. Neck circumference as a novel parameter to determine metabolic risk factors in obese children. Eur J Clin Invest. 2012;42(6):623-30. doi: 10.1111/j.1365 2362.2011.02627.x. [PubMed: 22129208].

18. Androutsos O, Grammatikaki E, Moschonis G, Roma-Giannikou E, Chrousos GP, Manios Y, et al. Neck circumference: a useful screening tool of cardiovascular risk in children. Pediatr Obes. 2012;7(3):187-95. doi: 10.1111/j.2047-6310.2012.00052.x. [PubMed: 22505226].

19. Guo X, Li Y, Sun G, Yang Y, Zheng L, Zhang X, et al. Prehypertension in children and adolescents: association with body weight and neck circumference. Intern Med. 2012;51(1):23-7. [PubMed: 22214619].

20. Katzmarzyk PT, Tremblay A, Perusse L, Despres JP, Bouchard C. The utility of the international child and adolescent overweight guidelines for predicting coronary heart disease risk factors. J clinical Epidemiol. 2003;56(5):456-62.

21. Nagy P, Kovacs E, Moreno LA, Veidebaum T, Tornaritis M, Kourides Y, et al. Percentile reference values for anthropometric body composition indices in European children from the IDEFICS study. Int J Obes (Lond). 2014;38 Suppl 2:S15-25. doi: 10.1038/ijo.2014.131. [PubMed: 25219408].

22. Kelishadi R, Ardalan G, Qorbani M, Ataie-Jafari A, Bahreynian M, Taslimi M, et al. Methodology and Early Findings of the Fourth Survey of Childhood and Adolescence Surveillance and Prevention of Adult Non-Communicable Disease in Iran: The CASPIAN-IV Study. Int J Prev Med. 2013;4(12):1451-60. [PubMed: 24498502].

23. Kelishadi R, Motlagh ME, Bahreynian M, Gharavi MJ, Kabir K, Ardalan G, et al. Methodology and Early Findings of the Assessment of Determinants of Weight Disorders among Iranian Children and Adolescents: The Childhood and Adolescence Surveillance and PreventIon of Adult Noncommunicable Disease-IV Study. Int J Prev Med. 2015;6:77. doi: 10.4103/2008-7802.162953. [PubMed: 26425332].

24. Cole TJ, Green PJ. Smoothing reference centile curves: the LMS method and penalized likelihood. Statistic Med. 1992;11(10):1305-19.

25. Sizonenko P. Physiology puberty. J Cendocrinological Invest. 1988;12(8):59-63.

26. Armstrong S, Lazorick S, Hampl S, Skelton JA, Wood C, Collier $D$, et al. Physical Examination Findings Among Children and Adolescents With Obesity: An Evidence-Based Review. Pediatrics. 2016;137(2):20151766. doi:10.1542/peds.2015-1766. [PubMed: 26817935]

27. Jensen NS, Camargo TF, Bergamaschi DP. Comparison of methods to measure body fat in 7-to-10-year-old children: a systematic review. Public Health. 2016;133:3-13. doi: 10.1016/j.puhe.2015.11.025. [PubMed: 26774698]

28. Kiekkas P, Stefanopoulos N, Bakalis N, Kefaliakos A, Konstantinou E. Perioperative Adverse Respiratory Events in Overweight/Obese Children: Systematic Review. J Perianesth Nurs. 2016;31(1):11-22. doi: 10.1016/j.jopan.2014.11.018. [PubMed: 26847776]

29. Maltz L, Matz EL, Gordish-Dressman H, Pillai DK, Teach SJ, Camargo CA, et al. Sex differences in the association between neck circumference and asthma. Pediatr Pulmonol. 2016;51(9):893-900. doi: 10.1002/ppul.23381. [PubMed: 26774073].

30. Taheri M, Kajbaf TZ, Taheri MR, Aminzadeh M. Neck Circumference as a Useful Marker for Screening Overweight and Obesity in Children and Adolescents. Oman Med J. 2016;31(3):170-5. doi: 10.5001/omj.2016.34. [PubMed: 27162586].

31. Hosseini M, Ataei N, Aghamohammadi A, Yousefifard M, Taslimi S, Ataei $F$. The relation of body mass index and blood pressure in Iranian children and adolescents aged 7-18 years old. Iran J Public Health. 2010;39(4):126-34. [PubMed: 23113046].

32. Hosseini M, Baikpour M, Yousefifard M, Mansournia MA, Yaseri M, Asady H. Body Mass Index Percentile Curves for 7 To 18 Year Old Children and Adolescents; are the Sample Populations from Tehran Nationally Representative? Inter J Pediat. 2016;4(6):1926-34. 
33. Hosseini M, Kelishadi R, Yousefifard M, Qorbani M, Bazargani B, Heshmat R, et al. Height-adjusted percentiles evaluated central obesity in children and adolescents more effectively than just waist circumference. Acta Paediatr. 2017;106(1):112-9. doi: 10.1111/apa.13622. [PubMed: 27727475].
34. Hosseini M, Navidi I, Hesamifard B, Yousefifard M, Jafari N, Poorchaloo SR, et al. Weight, height and body mass index nomograms; early adiposity rebound in a sample of children in tehran, iran. Int J Prev Med. 2013;4(12):1414-20. [PubMed: 24498497]. 